\title{
A review and perspective on maximizing brain plasticity: priming the nervous system to learn
}

\begin{abstract}
Although we know the central nervous system is adaptable and can respond to learning based behavioral training to recover from trauma, disease or aging, in the clinic the effectiveness of recovery can be limited. Part of this limitation in recovery is due to the severity of the brain insult but part of this incomplete recovery is due to the conditions surrounding the individual patient that may need to be addressed to maximize plasticity. In this brief review, a perspective on the need to prime the nervous system to learn is provided for consideration and reflection.
\end{abstract}

Volume I Issue 5 - 2017

\author{
Nancy Byl \\ Department of PT and Rehabilitation Science, University of \\ California, USA \\ Correspondence: Nancy Byl, Department of PT and \\ Rehabilitation Science, University of California, San Francisco, \\ USA, Tel 415514 48I6, Fax 415514 48I7, Email ByIN@ucsf.edu
}

Received: August 20, 2017| Published: September 0I, 2017

\section{Introduction}

We are in the midst of a Brain Plasticity Revolution. ${ }^{1-7}$ Today we know our brain's machinery is undergoing continuous rewiring throughout our lifetime even in the face of an injury. ${ }^{3-6}$ Neuro plasticity serves as a primary source for the maintenance of refined skills and abilities despite aging. ${ }^{6}$

Fifty years ago, students learned the nervous system was only adaptable and plastic during the developmental years, physical exercise was only needed if you were going to play a sport, heavy labor was a common component of traditional work, many were without cars and walked to work/school and the average longevity was less than 70 years. Today we are living longer, immobility is a primary health problem $^{8-10}$ falls in the elderly are common ${ }^{11}$ over 70 million people will be stroke survivors by $2030^{12,13}$ opiod addiction is a national crisis with serious adverse events. ${ }^{14,15}$ Alzheimer's Disease is considered as a "Type 3 Diabetes"7,16 stressful, stereotypical repetitive job tasks are degrading cortical representations and disrupting voluntary motor control ${ }^{17,18}$ auto immune diseases are on the rise and the population is consuming excessive amounts of gluten ${ }^{7,19,20}$ Gluten (a sticky protein) is associated with a leaky gut and an increase in inflammation and cytokines in the vital organs, especially the brain. ${ }^{7,10,19-22,}$

Since 1979, the World Health Organization has promoted adequate exercise, good nutrition, stress management and positive lifestyle behaviors as part of Healthy People $2000^{8,9,23-25}$ yet less than $50 \%$ of Americans meet the criteria recommended for physical activity. ${ }^{8,9,23-25}$ When the WHO guidelines are combined with recommendations for life long dynamic cognitive learning, it is not only possible to maintain cognitive, sensory and fine motor skills with clarity, reliability and efficiency despite aging, but also to maximize recovery and function from serious trauma, disease and cancer. ${ }^{1,3,8}$ Unfortunately, the growing science of positive health and brain plasticity in animal studies has not been associated with significant improvement in the clinical effectiveness of restoring community participation and quality of life for individuals with impairments. ${ }^{3,4,5}$

Over the last 10 years, researchers have clarified some basic guidelines to promote behavioral plasticity. ${ }^{1,2,4-6,26}$ These principles must be integrated into neurological rehabilitation strategies and activities of daily living (Table 1). Given some consumers and health care practitioners doubt the science of plasticity, it is not surprising some individuals are unwilling to commit to exercise, follow a nutritious diet, drink adequate fluids, achieve adequate sleep, address stress, stop smoking or decrease ETOH consumption Thus, a large percent of the population is pathologically overweight, depressed, isolated, challenged with chronic pain and have lost the motivation to learn, think positively and set meaningful goals ${ }^{8,10}$ These individuals put physiological systems, especially the brain, at risk for oxygen deprivation and central hypersensitivity $3,8,9,14,23,24$ Further, while older people are worried about developing Alzheimer's disease as a consequence of aging, many still chose to isolate themselves at home and disengage from challenging learning activities ${ }^{9,6}$ In fact, these life style issues may contribute more to falls and cognitive decline than aging or genetics. ${ }^{8,9,27}$

Table I Principles of experience dependent plasticity $3,5,22,24$

\begin{tabular}{ll}
\hline Expect to improve & $\begin{array}{l}\text { Make learning fun } \\
\text { Use it or lose it }\end{array}$ \\
Use, remap and improve it & Adjust training to be age \\
Include adequate repetitions & relevant \\
Make training intense (2-8 & Reinforce learning with \\
hrsiday, 2-5 days/week) & feedback/accuracy \\
Space training over time & Transfer learning to new \\
Attend to training activities & situations \\
-Vary training sequence & Strengthen learning with \\
Progress task difficulty & interference /surprise \\
-Be specific & \\
\hline
\end{tabular}

To facilitate maximum neuroplasticity the body, especially the brain, may need to be "primed" for learning. For example, for many individuals, priming the nervous system may begin with medical treatment strategies (eg. medications, surgery, radiation). Prescription medications can help manage a variety of conditions (eg high blood pressure, diabetes, seizures, spasticity, dystonia, anxiety, depression, pain). However, if the patient does not self manage other behavioral and environmental issues like stress, sleep, nutrition, exercise, and hydration, then the prescription medications cannot be effective. ${ }^{14,18}$ 
Priming the brain to learn may also be accomplished by simply helping patients develop a positive attitude (e.g. expecting to age gracefully or recover quickly from a minor injury). ${ }^{14}$ Educating the patient to accept that pain may be learned and persistent even after the injured tissues have healed can also be considered priming. ${ }^{14,15,28}$ In other cases, giving positive feedback (e.g. a follow up phone call) may help keep patients committed to carrying out their exercises. ${ }^{4-6,11,23}$ General physical exercise can also be viewed as type of priming for the nervous system to learn. Physical activity can improve cardiopulmonary dysfunction, metabolism, oxygen delivery, weakness, inflexibility, edema and degenerative joints. ${ }^{8,6}$ Healthy eating (e.g. avoiding excessive glutens, fats, sugar) smoking cessation and reducing alcohol can also be considered primers for the nervous system to learn by decreasing secondary diabetes, kidney disease, heart attacks and cancer., ${ }^{7,26}$

For those who suffer challenging brain trauma, musculoskeletal injuries or neurodegenerative disease, life style components may need to be supplemented with novel priming strategies. For example, there is evidence remote ischemic limb condition (RILC) can prime the heart and the brain to tolerate heart surgery. ${ }^{29,30,27}$ There is also early evidence the same RILC techniques can prime the brain for more efficient motor learning even in healthy individuals. ${ }^{29}$ In other situations, repetitive transmagnetic stimulation (rTMS) may improve connectivity and reorganization when delivered prior to retraining for patients post stroke ${ }^{31,32}$ or those with movement disorders like dystonia. $^{33,34}$ If fascia is tight, retinaculum thicker than normal or joints are restricted from scarring or aging, negative compression techniques, soft tissue mobilization and/or joint manipulation may be needed to prime the neuromusculoskeletal system to move and allow restoration of normal biomechanics and mobility. ${ }^{35-37}$ In other cases, assistive robotics may prime the neuromusuloskeletal system to move, initiating the potential to recover normal voluntary movements. ${ }^{38}$

In summary, the brain is soft wired. Neuroplasticity is a process which can continue across the lifespan when paired with positive life style behaviors, dynamic learning and physical activities. Exploiting neural adaptation may require initial neural priming, especially for individuals challenged with disease, injury and degeneration. When the brain is primed and ready to learn, the science and principles of plasticity can be integrated more effectively.

\section{Acknowledgements}

None.

\section{Conflict of interest}

The author declares no conflict of interest.

\section{References}

I. American Physical Therapy Association Section on Neurology, 20122013. USA: Neuroplasticity Continuing Education Course; 2012.

2. Byl NN, Merzenich MM. Principles of Neuroplasticity, Physiological Basis of Rehabilitation. 3rd ed. UK: Butterworth Heineman; 2000.

3. Doidge N. The Brain that Changes Itself. New York: Penquin Group; 2015.

4. Ebner FF. Neural Plasticity in Adult Somatic Sensory-Motor Systems. Chapter II Behavioral Basis of Focal Hand Dystonia;Aberrant Learning in the Somatosensory Cortex: USA:Taylor \& Francis; 2005.

5. Ebner FF. Neural Plasticity in Adult Somatic Sensory-Motor Systems. In: Neural plasticity in the Adult Motor Cortex. USA:Taylor \& Francis; 2005.
6. Merzenich. M Soft Wired How the New Science of Brain Plasticity Can Change Your Life. San Francisco: Parnassus Publishing LLC; 2013.

7. Perlmutter. David Grain Brain. USA: Little Brown and Company; 2013.

8. Department of Health and Human Services Healthy People; 2000.

9. Fletcher GF, Balady G, Blair SN, et al. Statement on Exercise: Benefits and recommendations for Physical Activity Programs for All Americans. Circulation. 1996;94(4):857-862.

10. Hu WT, Murray JA, Greenaway MC, et al. Cognitive impairment and celiac disease. Arch Neurol. 2006;63(I0): I440-I446.

I I. Sinha SK, Detsky AS. Measure, promote and reward mobility to prevent falls in older patients. JAMA. 2012;308(24):2573-2574.

12. Feigin VL, Forouzanfar MH, Krishnamurthi R et al. Global and regional burden of stroke during 1990-2010 Findings from the global burden of disease study 2010. Lancet. 2014;383(9913):245-254.

13. Mozaffarian D, Benjamin EJ, Go AS, et al. Heart disease and stroke statistics-2016 update. Circulation. 2015;133(4):e38-e360.

14. Mosely L, Butler DS. Fifteen Years of Explaining Pain: The Past, Present, and Future.J Pain. 20I5; I6(9):807-8I3.

15. Yamato TP, Maher CG, Saragiotto BT, et al. Comparison of effect sizes between enriched and nonenriched trials of analgesics for chronic musculoskeletal pain: a systematic review. Br J Clin Pharmacol. 2017; 83(II):2347-2355.

16. Steen E, Terry BM, Rivera EJ, et al. Impaired insulin and insulin-like growth factor expression and signaling mechanisms in Alzheimer's Disease--Is this type 3 Diabetes? J Alzheimer's Disease. 2005;7(I):63-80.

I7. Byl N,Merzenich M,JenkinsW.A Primate Genesis Model of Focal Dystonia and Repetitive Strain Injury: I. Learning-Induced De-differentiation of the Representation of the Hand in the Primary Somatosensory Cortex in Adult Monkeys. Neurology. 1996;47(2):508-520

18. loannou $\mathrm{Cl}$, Furuya S, Altenmüller $\mathrm{E}$. The impact of stress on motor performance in skilled musicians suffering from focal dystonia: Physiological and psychological characteristics. Neuropsychologia. 2016;85:226-236.

19. Hadjivassilou M, Sanders DS, Grünewald RA, et al. Gluten sensitivity: from gut to brain. Lancet, Neuroogy. 2010;9(3):318-330.

20. http://www.celiaccenter.org/

2I. Davis W.Wheat Belly. New York: Rodale Books; 201 I.

22. Rubio PJM, Morillas RJM. A review: inflammatory process in Alzheimer's Disease, role of cytokines. Scientific World Journal. 2012.

23. American Academy of Sports Medicine (ACSM), the american heart association (AHA): support of federal physical activity guidelines. matrix administration; $20 \mathrm{II}$.

24. Brown CJ, Redden DT, Flood KL, et al. The under-recognized epidemic of low mobility during hospitalization of older adults. J Am Geriatr Soc. 2009;57(9):1660-1665.

25. World Health 10 facts on physical activity. Switzerland:WHO/V Collazos; 2013.

26. Kleim JA, Jones TA. Principles of Experience-Dependent Neural Plasticity: Implications for Rehabilitation After Brain Damage.J Speech Lang Hear Res. 2008;5 I (I I):S225-S239.

27. Giehl KM, Schutte A, Mestres P, et al. The survival-promoting effect of glial cell line-derived neurotrophic factor on axotomized corticospinal neurons in vivo is mediated by an endogenous brain-derived neurotrophicfactor mechanism. J Neurosci. 1998;8(I8):735I-7360. 
28. Traeger AC, Hübscher M, Henschke N, et al. Effect of Primary CareBased Education on Reassurance in Patients With Acute Low Back Pain Systematic Review and Meta-analysis. JAMA Intern Med. 20I5; I75(5):733744.

29. Cherry AKM, Gidday JM, Lee JM, et al. Remote limb ischemic conditioning enhances motor learning in healthy humans. J Neurophysiol. 20I5; II3(I0):3708-3719.

30. Gidday JM. Cerebral preconditioning and ischemic tolerance. Nat Rev Neurosci. 2006;7(6):437-448.

31. Carey JR, Anderson DC, gillickc BT, et al. 6- $\mathrm{Hz}$ primed low-frequency RTMS to contralesional $\mathrm{MI}$ in two cases with middle cerebral artery stroke. Neurosci Lett. 2010;469(3):338-342.

32. Grefkes CI, Nowak DA,Wang LE, et al. Modulating cortical connectivity in stroke patients by RTMS assessed with fMRI and dynamic causal modeling. Neurolmage. 2010;50(I):233-242.
33. KimberleyT], Borich MR,Arora S, et al. Multiple sessions of low-frequency repetitive transcranial magnetic stimulation in focal hand dystonia: clinical and physiological effects. Restor Neurol Neurosci. 20I 3;3 I (5):533-542.

34. Lozeron P, Pujois A, Richard, A, et al. Contribution of TMS and rTMS in the Understanding of the Pathophysiology and in the Treatment of Dystonia. Front Neural Circuits. 2016; I0(90): I-14.

35. Myers TW. Myofascial Meridians for Manual and Movement therapists Anatomy Trains. Churchill Livington: UK; 2001.

36. Torres JAKL, Rosales RL. Nonmotor Symptoms in Dystonia. Int Rev Neurobiol. 2017;134:I335-I37I.

37. Threlkeld AJ.The effects of manual therapy on connective tissue. Physical Therapy. 1992;72(12):893-902.

38. Norouzi-Gheidari, N, Archambault PS, Fung J. Effects of robot assisted therapy on stroke rehabilitation in upper limbs: Systematic review and meta analysis of the literature.J Rehabil Res Dev. 2012;49(4):479-496. 